\title{
A complete comparison between JUTTON \& COTTON-increase jute dependency instead of
} \section{cotton}

\begin{abstract}
Jute producing sector is one in every of the oldest ancient manufacturing sectors of East Pakistan. As a lignocellulosic natural fibre jute possesses exhausting and harsh qualities that build it troublesome to provide attire and alternative fancy materials used in our daily life. Jute-Cotton mix is one in every of the doable choices to cut back the reliableness on the cotton. The aim of this work is to characterize the Jute-cotton alloyed material. During this work 100 gift cotton material is compared with a jute-cotton alloyed fabric. material samples like weave style, yarn count, material density, cowl issue, weight per unit space $\left(\mathrm{g} / \mathrm{m}^{2}\right)$, material strength, colouring performances like wash and rubbing fastness are evaluated. The reflection factor attempt to color strength $\mathrm{K} / \mathrm{S}$ values of reactive colored material and basic dyed fabric samples were additionally studied. The experimental works are done at Dyeing laboratory and textile testing \& quality control laboratory of Textile Engineering College, Noakhali.
\end{abstract}

Keywords: jute-cotton blended fabric, fabricdensity, cover factor, weight per unit area $\left(\mathrm{g} / \mathrm{m}^{2}\right)$
Volume 6 Issue 4 - 2020

\author{
Syed Tanvir Hasan,' Md Mahfuz Alam, ${ }^{2}$ \\ Rezwan Sal Sabil,' Md Solaiman Bari² \\ 'Department of Yarn Manufacturing Engineering, Textile \\ Engineering College, Noakhali affiliated by Bangladesh University \\ of Textiles, Tejgaon, Dhaka- I208, Bangladesh \\ ${ }^{2}$ Department of Fabric Manufacturing Engineering, Textile \\ Engineering College, Noakhali affiliated by Bangladesh University \\ of Textiles, Tejgaon, Dhaka-1208, Bangladesh
}

Correspondence: Syed Tanvir Hasan, Department of Yarn Manufacturing Engineering. Textile Engineering College, Noakhali affiliated by Bangladesh University of Textiles, Bangladesh. Tel +8801793 I66322, Email Tanvir.syedhasan@gmail.com

Received: June 17, 2020 | Published: July 09, 2020

\section{Introduction}

Jute fibre is a natural bast fibre which is obtained from the bark of jute plant, consist of three main categories of chemical compounds named cellulose (58 63\%), hemi-cellulose $(20 \sim 24 \%)$ and lignin (12 15\%), and some other small amount of constituents such as fats, pectin, aqueous extract. Jute fibre is consisting of small units of cellulose enclosed and attached together by lignin and hemi-cellulose (Pan et al., 1999). Jute fibre is not used to produce wearable product as it has some faults in regard to feel, drape, stiffness, wash ability coarseness and abrasion (Azad et al., 2009). At present, in jute sector, need of diversified jute been used and improved quality is rising for the use in various areas namely floor coverings, technical textiles, household textiles, handicrafts and so on. (Sengupta et al., 2012). Blending is a technique used to remove the poor characteristics of one fibre. It is a technique which is used to combine fibres that emphasizes the good qualities in the same time minimizes the poor qualities of the fibres. It also reduces the manufacturing cost of fabric production and makes it economical. Jute-cotton blended yarn is one of the examples of it (Bhardwaj et al., 2012). Blending jute with cotton fibre may be an acceptable the process of jute diversification by which valueadded products can be produced. Jute fibres have several advantages like high tenacity, a lustrous golden appearance and good properties. Hence the techniques of softening and blending could as utilize to increase the quality of jute and can form a new class of jute-based fabrics which may have an expanding market within and outside the country (Shilpa et al., 2007).

In the present work, some characteristics of jute-cotton blended fabrics have been assessed. In comparison, characteristics of fabric which produced from JUTE-COTTON blended yarn is far better than characteristics of the fabric produced from single yarn. The blending of jute and cotton is done to develop comfortability, drape properties, wash fastness, dyeability many other properties of the fabric products. Any successful effort to blend cotton with jute fibre would be a break- through in the field of textile. ${ }^{1}$ The use of fabrics made from JuteCotton blended yarns would surely Strength our economy by cutting a part of the cost incurred for importing cotton and enhancing the value addition due to locally produced cheaper jute as a raw material (Ahmedullah et al., 2012).

\section{Methods and materials}

\section{Preparation of fabrics}

We considered one hundred percent plain $(1: 1)$ cotton fabric, which contains 105 Ends per inch and 75 Picks per inch. Where warp yarn is $54 \mathrm{Ne} \&$ weft yarn is $38 \mathrm{Ne}$.

In the same time, we considered a Jute-Cotton Blended fabric, which Contains 48 Ends per inch \& 28 Picks per inch where warp yarn count is $15 \mathrm{Ne} \&$ weft yarn count is $30 \mathrm{Ne}$.

\section{Strength evolution}

The Force-Elongation results of the fabric samples were determined by Universal Tensile Strength Tester GESTER (GT-CO2) at $300 \mathrm{~mm} /$ min test speed. The fabric samples were $15 \mathrm{~cm} \times 10 \mathrm{~cm}$ attached with the upper clamp and lower clamp and the samples were tested with the mentioned speed.

\section{Weight per unit area}

Gram per square meter (G.S.M) of both fabrics was calculated with the relationship,

$$
\text { G.S.M }=\left[\frac{\mathrm{EPI}}{\operatorname{Warp} \operatorname{count}(\mathrm{Ne})}+\frac{\mathrm{PPI}}{\text { Weft } \operatorname{count}(\mathrm{Ne})}\right] \times 23.50
$$

Where EPI indicates Ends per inch and PPI indicates Picks per inch of the fabrics. 


\section{Fabric drape test}

Drape co-efficient $=($ Total mass of the shaded area/total mass of paper ring) 100

The procedure was followed through (ISO 9073-9:2008)

\section{Rubbing fastness}

Rubbing color fastness defined as the power to continue first color of dyed fabrics when rubbing.

Dry rubbing test was carried out using the grayscale for staining under standard lighting, D65.One test is done to warp direction \& another for warp direction.

Wet rubbing test carried out by wetted with water to $100 \%$ take up. Air dries the both cotton \& jute-cotton blended test at the room temperature. For this it is also done to warp direction $\&$ another for warp direction.

Test is followed in (ISO 105X12; 1993; BS EN ISO 105X12; 1995) for both fabrics.

\section{Pilling test}

Pilling is a fabric surface characteristic caused by little pills of entangled fibre adjacent to the cloth surface and giving the garment haggish appearance. Under the impact of the rubbing action these unbound fibres develop into small circular bundles hang on to the fabric by a few unbroken fibres. Test is done through (ICI Pilling Box) (ISO 12945-1).

\section{Cloth cover}

The cloth cover may define as the fabric construction displaying to what boundary the warp and the weft yarns are clearly woven and become acquired from the below,

$$
\mathrm{K}_{\mathrm{c}}=\mathrm{K}_{1}+\mathrm{K}_{2}-\mathrm{K}_{1} \mathrm{~K}_{2} / 28
$$

Where, $\mathrm{K}_{\mathrm{c}}=$ Cloth cover

$\mathrm{K}_{1}=$ Warp cover factor

$\mathrm{K}_{2}=$ Weft cover factor

The fraction of space per inch of cloth covered by warp yarn is known as warp cover factor which was obtained as,

$$
K=\frac{\text { Threads per inch }}{\sqrt{\text { Count }}}=\frac{n}{\sqrt{N e}}
$$

Similarly, the weft cover factor was calculated. The threads per inch $n$ were counted with the help of thread counter.

\section{Measurement of reflectance (\%) and color strength (K/S)}

Reflectance of any dyed fabric samples and Dyed fabrics color depth was analysed by measuring the K/S values of samples. Color measuring instrument called Spectrophotometer (Data color) determines the Reflectance (\%) and Color depth (K/S) value of fabrics were measured \& compered using a UV VIS-NIR reflective spectrometer (Spectra flash SF 600 X, USA), over the range of 400 to $700 \mathrm{~nm}$.

The equation which we get from Kubelka-Munk is following,

$\mathrm{K} / \mathrm{S}=\left[\left\{(1-\mathrm{R})^{2} / 2 \mathrm{R}^{2}\right\}\right]$

Where, $\mathrm{R}=$ Reflectance

$\mathrm{K}=$ Absorbance

$\mathrm{S}=$ Scattering

\section{Wash fastness}

The colour fastness to wash of a dyed cloth is the measure of its counteraction in shade exchange, on publicity to a given organization or treatment. For both fabrics (ISO 105 C06) method was followed.

\section{Results and discussions}

\section{Jute-cotton blended fabric \& cotton fabric}

Fabric samples details made from the jute-cotton blended fabric $\&$ cotton fabric have been plotted in the Table 1. Both jute-cotton blended fabric \& cotton fabric are in plain weave structure, because normally woven fabrics are of plain structural pattern. The variations in the amount of threads per unit length of fabric is in related to the yarn count $\mathrm{Ne}$, but the cover factors for both warp and weft and ensuing impact at the cloth became maintained nearly identical. The fabric sample A was represented with Jute-cotton blended fabric with ratio $1 / 1$ plain structured, warp yarn count was 15 and weft yarn count was 30 , total no. of warp yarn and weft yarn per inch were 48 and 28 respectively, the cover factor was 14.86 and weight per unit area was $97 \mathrm{~g} / \mathrm{m}^{2}$. The fabric sample B was represented with hundred percent cotton fabric, 1/1 plain structured, warp yarn count was 54 and weft yarn count was 38 , total no. of warp yarn and weft yarn per inch were 105 and 75 respectively, the cover factor was 20 and weight per unit area was $92 \mathrm{~g} / \mathrm{m}^{2}$.

\begin{tabular}{|c|c|c|c|c|c|c|}
\hline Fabric Sample & Yarn composition & Weave design & Yarn count $(\mathrm{Ne})$ & Threads per inch & Cover factor & Weight $\mathbf{g} / \mathrm{m}^{2}$ \\
\hline \multirow{3}{*}{ A } & \multirow{3}{*}{$\begin{array}{l}\text { Jute-Cotton Blended } \\
\text { Fabric }\end{array}$} & \multirow{3}{*}{ I/I Plain } & Warp I5 & Ends 48 & \multirow{3}{*}{14.86} & \multirow{3}{*}{97} \\
\hline & & & & & & \\
\hline & & & Weft 30 & Picks 28 & & \\
\hline \multirow{3}{*}{ B } & \multirow{3}{*}{ Cotton } & \multirow{3}{*}{ I/I Plain } & Warp 54 & Ends 105 & \multirow{3}{*}{20} & \multirow{3}{*}{92} \\
\hline & & & & & & \\
\hline & & & Weft 38 & Picks 75 & & \\
\hline
\end{tabular}

Table I Fabric construction of jute-cotton blended fabric \& cotton fabric 


\section{Strength evolution}

After completing the test of Force-Elongation of both samples in GESTER (GT-C02) at a speed of $300 \mathrm{~mm} / \mathrm{min}$ we get the following results which presents the change of characteristics of the blended with the respect of hundred percent cotton fabric, plotted in Table 2.

\section{Fabric drape test}

Drape co-efficient for Jute-Cotton blended fabric $=(1.123 /$ 7.244) $100=15.44 \%$

Drape co-efficient for $100 \%$ Cotton fabric $=$ 7.244) $100=41.62 \%$

Table 2 The change of characteristics of the blended with the respect of hundred percent cotton fabric

\begin{tabular}{llll}
\hline Sample & Elongation at break (\%) & Breaking strength $(\mathbf{N})$ & Tensile strength $\left(\mathbf{N} / \mathbf{m m}^{2}\right)$ \\
\hline Jute-Cotton blended fabric & 9.49 & 433.565 & 4.886 \\
$100 \%$ Cotton fabric & 6.4 & 258.485 & 4.507
\end{tabular}

\section{Fabric rubbing test}

From the Table 3 it is far seen that the dry rubbing fastness of sample A (Jute-Cotton blended fabric) was almost same with the sample B (100\% Cotton fabric) with the value $4-5$ and 5 respectively. The wet rubbing fastness is also for sample A (Jute-Cotton blended fabric) is similar to sample B (100\% Cotton fabric). The values are 2 and 2-3 respectively. As the sample A (Jute-Cotton blended fabric) was dyed with basic \& reactive dyes and the fabric of sample B $(100 \%$ Cotton fabric) was dyed with reactive dyes. So, the rubbing fastness of sample A (Jute-Cotton blended fabric) is similar to the sample B (100\% Cotton fabric) that we can say.

Table 3 Rubbing fastness test result of Jute-cotton blended fabric

\begin{tabular}{lll}
\hline Type of rubbing & Sample A & Sample B \\
\hline \multirow{2}{*}{ Dry rubbing } & $4-5$ & 5 \\
& 4 & 5 \\
& $4-5$ & 5 \\
Wet rubbing & 2 & $2-3$ \\
& $1-2$ & 3 \\
\hline
\end{tabular}

\section{Wash fastness}

From the Table 4 it was found that dyes stained on the fibers of the multifiber fabric show the rating is almost same for both the fabrics. The sample A was dyed with reactive dye and the warp yarn of the sample B was dyed with indigo dyes. The staining on the di-acetate, cotton, nylon, polyester, acrylic, wool for sample A and B was found in good rating value 3 to 4 (Figure 1).

Table 4 Staining on the multifibre due to wash of different Jute-Cotton blended fabric

\begin{tabular}{lll}
\hline Multifibre & Cotton & Jutton \\
\hline Di-acetate & $2-3$ & $2-3$ \\
Bleached Cotton & $3-4$ & 3 \\
Polyamide & 3 & 1 \\
Polyester & 5 & 5 \\
Acrylic & 4 & $4-5$ \\
Wool & 2 & 1 \\
\hline
\end{tabular}

\section{Wash Fastness}

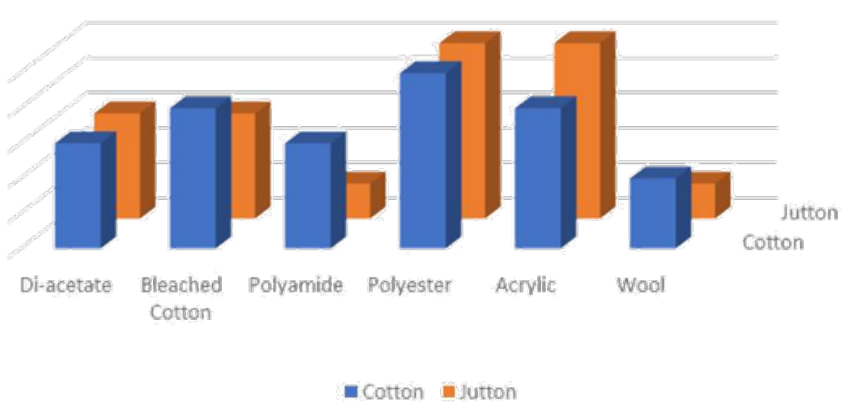

Figure I Wash fastness.

\section{Pilling test}

After 18000 cycle of running in the ICI pilling box. We found following result in 3:3 total 6 samples (Table 5) (Figure 3).

Table 5 Samples

\begin{tabular}{lll}
\hline Sample & $\begin{array}{l}\text { Jute-Cotton blended } \\
\text { fabrics rating }\end{array}$ & $\begin{array}{l}\text { Cotton fabrics } \\
\text { rating }\end{array}$ \\
\hline Sample 01 & 4 & 5 \\
Sample 02 & 4 & 5 \\
Sample 03 & 4 & 5 \\
\hline
\end{tabular}

\section{Reflectance evaluations}

Figure 3 shows the reflectance (\%) of sample Cotton \& sample Jutton. It is known that, when reflectance is more, absorbance is less. Reflectance (\%) was measured in.

\section{Pilling Test}

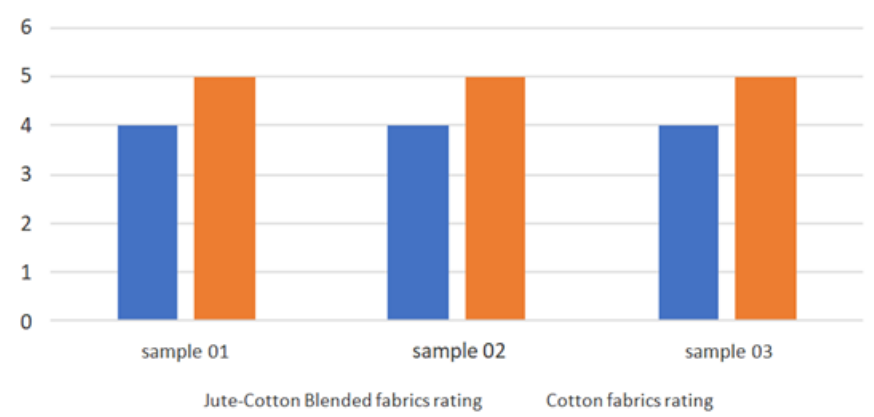

Figure 2 Pilling test. 


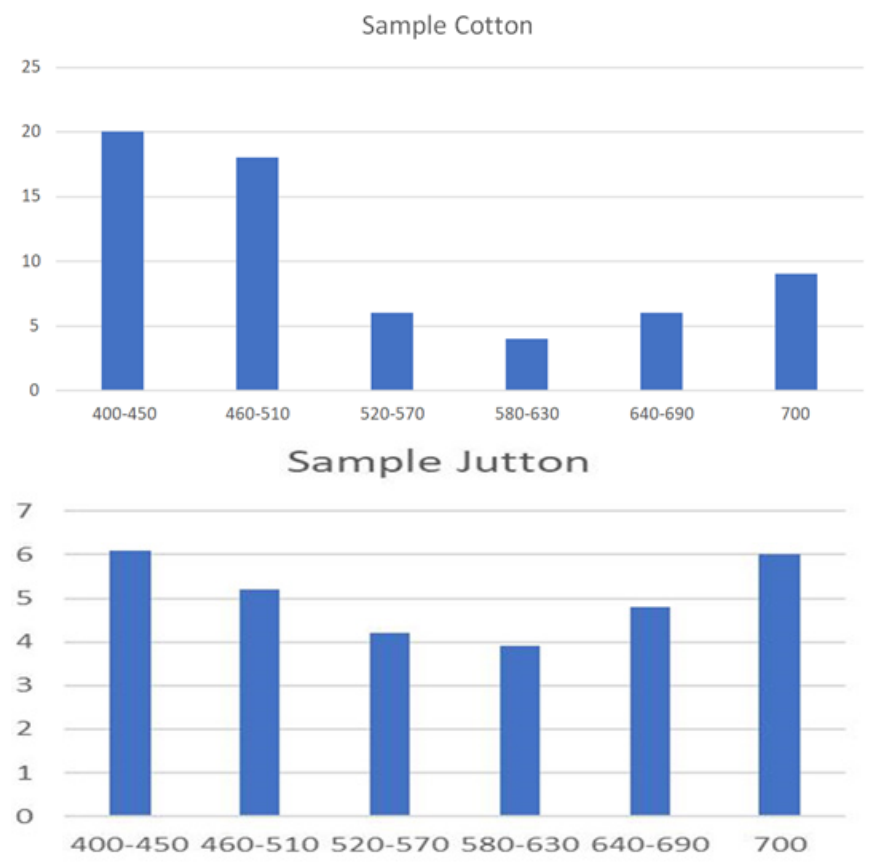

Figure 3 The reflectance (\%) of sample Cotton \& sample Jutton.

400-450, 460-510, 520-570, 580-630, 640-690 and 700nm wave lengths. For sample Cotton the reflectively $\%$ was $20,18.36,6.61,4.0$, 6.31 and 9.44 respectively. For sample Jutton, the reflectance \% was $6.26,5.57,4.49,3.91,4.79$, and 5.65 respectively.

\section{$\mathrm{K} / \mathrm{S}$ evaluation}

Color strength of sample Cotton and sample Jute was measured through $\mathrm{K} / \mathrm{S}$ value and graphically represented in Figure 4 . When the reflectance is more, absorbance is less. On the other hand, when reflectance is less; absorbance is more, indicates the more $\mathrm{K} / \mathrm{S}$ value. $\mathrm{K} / \mathrm{S}$ value was measured in $400-700 \mathrm{~nm}$ wave lengths. For example, Cotton, the K/S value was lowest 1.6 at $450 \mathrm{~nm}$ and highest value was 11.93 at $610 \mathrm{~nm}$, for sample Jute the K/S was minimum 7.01 at $430 \mathrm{~nm}$ and maximum 12.35 at $630 \mathrm{~nm}$ wave lengths..$^{2-21}$

K/S Graph of Sample Cotton

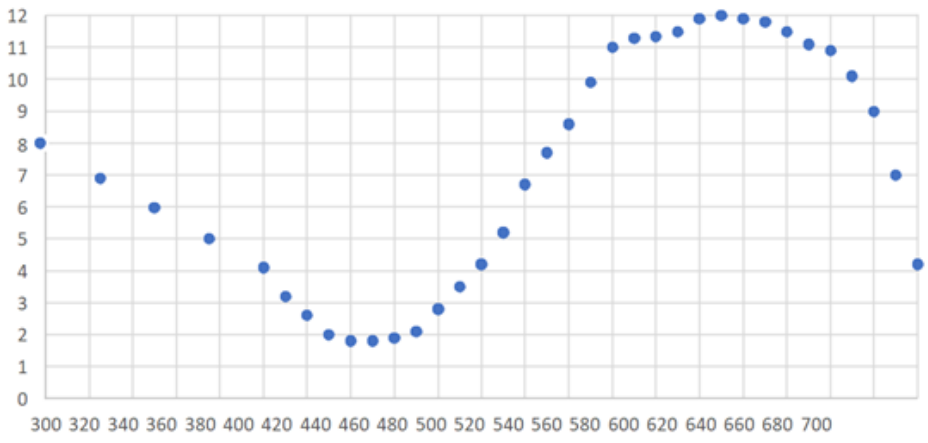

K/S Graph of Sample Jutton

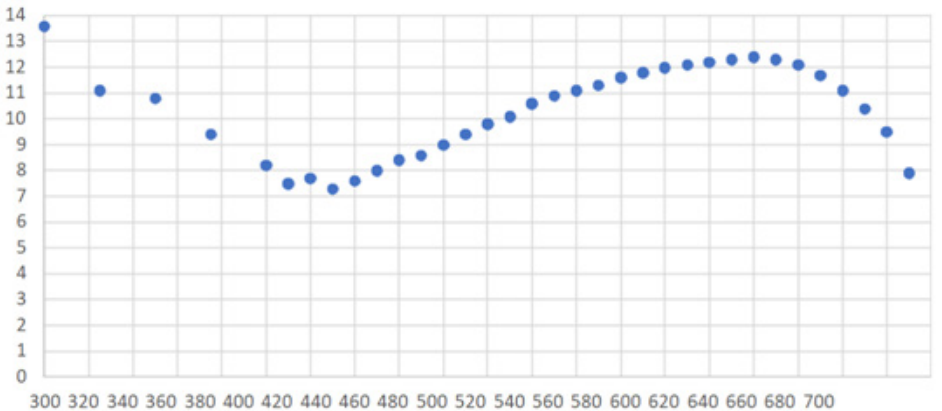

Figure $4 \mathrm{~K} / \mathrm{S}$ graph of sample Cotton \& sample Jutton. 


\section{Conclusion}

The jute-cotton blended fabric which also called jutton and hundred present cotton which was characterized on weave design, yarn count, fabric density, cover factor, weight per unit area (g/ $\mathrm{m}^{2}$ ), fabric strength, dyeing performances such as wash and rubbing fastness, reflectance and color strength. The study reveals that, the characteristics of blended yarn fabric can be used as fully cotton fabric which may reduce the dependability on importable cotton fibre. Statistically all the major results are shown that jute-cotton blended fabric can be used instead of hundred percent cotton fabrics. On the whole, it may be said that, not only depending on the cotton fibre, but also jute-cotton blending may reduce the dependability on $100 \%$ cotton yarn. The use of fabrics made from Jute-Cotton blended yarns would surely strengthen our economy by cutting a part of the cost incurred for importing cotton and enhancing the value addition due to locally produced cheaper jute as a raw material, an opportunity to integrate the blended yarn into the production of jute-cotton denim and other heavy fabrics also.

\section{Acknowledgments}

None.

\section{Funding}

None.

\section{Conflicts of interest}

The authors have no conflicts of interest regarding the publication of this paper.

\section{References}

1. Salam MA, Farouqui FI, Mondal MI. A study on sulphonated jute-cotton blended yarn and fabrics jute-cotton blended yarn and fabrics and their characteristics. Bangladesh Journal of Scientific and Industrial Research. 2007;42(3):281-286.

2. Talukdar MK, Sriramulu PK, Ajgaonkar DB. Weaving: machines, mechanisms, management. Mahajan Publishers; 1998.

3. Shahid MA, Ahmed F, Mahabubuzzaman AKM. Study on the physical properties of jute-cotton blended rotor yarn. SUST Journal of Science and Technology. 2012;20(6):84-88.

4. Charankar SP, Verma V, Gupta M. Growing importance of cotton blends in apparel market. Journal of the Textile Association. 2007;67(5):201-210.
5. Solaiman JS. Comparative analysis of manual fading and laser fading process on denim fabric. Science Discovery. 2015;3(6):44-49.

6. Barsha UH, Uddin M, Hasan M. Investigation on physical properties of jute cotton (jutton) blended fabric. 2018.

7. Ullah AA, Foisal ABM, Nahar N. Study on the characteristics of jutecotton blended fabrics.

8. Booth JE. Principles of textile testing. 1970.

9. Needles HL. Textile fibers, dyes, finishes, and processes: a concise guide. 1986.

10. Broadbent AD. Basic principles of textile coloration. 2001.

11. Belal SA. Understanding textile for a merchandiser. 2018.

12. Hossain ML. Practice of textile coloration. 2005.

13. Phillips D, Scotney J, Kenyon D. Application of the proposed ISO 105C09 single cycle test to predict the oxidative-bleach colour fading of dyed cotton fabrics to repeated laundering with a detergent base containing different bleach andbleach-activatorsystems. Coloration Technology. 2001;117(5):247-250.

14. Dann T, Malbon C. Tearing or ripping of fabrics. in forensic textile science. Woodhead Publishing; 2017:169-180.

15. Bulut MO, Akar E. Ecological dyeing with some plant pulps on woolen yarn and cationized cotton fabric. Journal of Cleaner Production. 2012;32:1-9.

16. Alpay HR, Becerir B, Akgun M. Assessing reflectance and color differences of cotton fabrics after abrasion. Textile research journal. 2005;75(4):357-361.

17. Jasińska I. Assessment of a fabric surface after the pilling process based on image analysis. Fibres \& Textiles in Eastern Europe. 2009;17(2):73.

18. Sanad R, Cassidy T, Cheung TLV. Fabric and garment drape measurement Part 1. Journal of Fiber Bioengineering and Informatics. 2012;5(4):341358.

19. Tapkin S. The effect of polypropylene fibers on asphalt performance. Building and Environment. 2008;43(6):1065-1071.

20. Bulut MO, Akar E. Ecological dyeing with some plant pulps on woolen yarn and cationized cotton fabric. Journal of Cleaner Production. 2012;32:1-9.

21. Järvinen P. Mapping of Jute's business opportunities in the Finnish market. Case: Tuli Trading Ltd; 2016. 